\title{
Spatial distribution characteristics and optimized reconstruction analysis of China's rural settlements during the process of rapid urbanization
}

\author{
Ren Yang ${ }^{\text {a, * }}$, Qian $\mathrm{Xu}^{\mathrm{a}}$, Hualou Long ${ }^{\mathrm{b},{ }^{* *}}$ \\ a School of Geography and Planning, Sun Yat-sen University, 135 West Xingang RD, Guangzhou 510275, PR China \\ ${ }^{\mathrm{b}}$ Institute of Geographic Sciences and Natural Resources Research, Chinese Academy of Sciences, 11A Datun Road, Chaoyang District, Beijing 100101, PR \\ China
}

\section{A R T I C L E I N F O}

\section{Article history:}

Received 28 October 2015

Received in revised form

5 May 2016

Accepted 6 May 2016

Available online 15 June 2016

\section{Keywords:}

Spatial distribution mode

Rural settlements

Geographical detector

Average nearest neighbor distance

Rural geography

China

\begin{abstract}
A B S T R A C T
The population density of rural areas is generally lower than before due to rapid industrialization. Spatial optimized reconstruction of rural settlements is the key to rural sustainable development. Analyzing the distribution characteristics of rural settlements and their impact has profound implications for rural reconstruction. Several types of spatial distribution of rural settlements, such as clustered, random, and uniform discrete distribution, were found in China with significant regional differences. Rural settlements were denser in the southeastern regions compared to the northwestern regions. In regions such as plains, the spatial distribution of rural settlements was denser and the spatial distribution modes were mainly random and disperse. In regions such as cold alpine areas and desert fringes, the rural settlements density was low and mainly clustered. In the transition zone between hills and mountains, the density of rural settlements was high and the spatial distribution mode was mainly random. Rural settlements distribution was influenced by traditions and the economy, with economic development becoming increasingly influential. Additional factors that affected rural settlements distribution included average distance to main roadway, agricultural machinery, per capita grain production, per capita arable land, population density, elevation, precipitation, etc. Multiple distribution patterns should be used to reconstruct rural spaces in different geographical areas. Typical patterns included radially balanced, central land distribution mode; radially imbalanced distribution mode; multicore central land distribution mode, and corridor balanced and imbalanced distribution modes.
\end{abstract}

(c) 2016 Elsevier Ltd. All rights reserved.

\section{Introduction}

Since 1978 (when China launched reforms and opened its borders), China's economy has been developing rapidly, with increasingly improved standards of living for most of the population (Bai et al., 2014). With rapid industrialization and the continuous socioeconomic progress of China, the spatial distribution of rural settlements has undergone significant transformation; this has revived interested in the study of social and economic problems of rural settlements (Liu and Yang, 2012; Yang et al., 2015a, 2015b, 2015c). Rural settlements are under significant pressure resulting

\footnotetext{
* Corresponding author.

** Corresponding author.

E-mail addresses: yangren666@mail.sysu.edu.cn, yangren0514@163.com (R. Yang), xuqian19840613@163.com (Q. Xu), longhl@igsnrr.ac.cn (H. Long).
}

from urbanization (Tan and Li, 2013) and experience significant changes as a consequence (Dumreicher, 2008). In rural areas, these settlements are important social units because they reflect the relationships between people and the land, the historical background, and the sociopolitical relationships (Jones, 2010; Robinson, 2003; Ottomano Palmisano et al., 2016). In China, rural reconstruction will play an important role in realizing the "Chinese Dream" of prosperity and sustainability in the next era of urbanization in China (Bai et al., 2014; Long et al., 2016). Rural transformation development involves reconstruction of rural settlements, rural production space, rural ecological space, and sociocultural space (Yang et al., 2015b). Globalization of the economy, regional differences in rural transformation development, changes in agriculture and village characteristics, and sustainable reconstruction of rural social economy have become essential research orientations when studying rural geography globally 
(Woods, 2005, 2007; Fink et al., 2013; Long et al., 2016). Rural transformation development involves transition of industrial structures and changes in agricultural enterprises, absolute employment in agriculture, agricultural productivity, the structure of rural settlements, and the sociocultural landscape (Long et al., 2012).

Rural settlement geography and urban settlement geography are the two areas that constitute the discipline of settlement geography, which itself is a recent branch of human geography (Cloke, 1979; Yang et al., 2015a). In other countries, studying rural settlement geography involves focusing on socialization and reconstruction of rural settlements (Terry, 1996). Rural sociology studies focus on social organizational construction, social change, rural community development, rural enterprises development, cultural patterns, and rural industrialization (William, 1964; Zhe, 1997; Huang, 2000; Ali, 2007; Marsden and Sonnino, 2008; Li et al., 2015; Liu et al., 2015). Studies of human geography have always paid attention to the spatial distribution of rural settlements. Between 1920s and 1960s, scholars in Europe and the US conducted a series of studies on the formation and development of rural settlements as well as their classification, functions, and planning (Jin, 1988; Jin et al., 1990). Christaller's central place theory represented a breakthrough in the academic understanding of this topic (Zhang, 1989; DeMarco and Matusitz, 2011). Quantitative approaches have been applied to examine rural development topics, especially regarding spatial distribution modes of rural settlements (Ripley, 1977; Ebdon, 1985). In behavioral science studies, researchers emphasize that there is a significant influence of human intervention on decisions regarding the distribution, form, and structure of rural settlements (Han and Cai, 2011; Shan et al., 2012; Liu et al., 2009; Li and Li, 2008; Long et al., 2009a; Hill, 2003). Recently, in the research area of the morphological differences and spatial patterns of rural settlements, several relevant foreign studies focused on the relationships among the rural population, rural industries, and settlements (Paul, 2009); effects of the type of rural settlements on public service facilities (Holmes, 2008); and evolution of the rural settlement landscape (Marc, 2004).

In China, rural settlements are defined as settlements that enable residents to primarily engage in agriculture, provide habitation for rural residents, and become developmental centers for rural communities (Zhou et al., 2013). Research on rural settlements started in the 1940s (Jin, 1988). During this period, research was focused on ancient architecture and traditional residences (demonstrating strong bias toward architecture) and rarely investigated characteristics of climate, geography, culture, and society. From the 1980s, research into rural settlements became multifaceted, multidirectional, and multidisciplinary (Yang et al., 2015a). Recently, researchers have investigated the system and structure of rural settlements in typical areas (Guo et al., 2012), the geographical types of rural settlements (Long et al., 2009b), evolution of rural settlements during industrialization and urbanization of China (Zhou et al., 2013; Liu et al., 2014; Xi et al., 2015), hollowing of rural settlements (Li et al., 2014), consolidation of rural land (Long et al., 2009a), optimized regulation of rural settlements (Liu et al., 2010; Long et al., 2012), and changes in rural settlements and housing land (Tian et al., 2007; Long and Li, 2012). Most of the recent research focused on eastern coastal areas (Su et al., 2011), Loess Plateau of China (Guo et al., 2012), and the mountainous regions of Sichuan province (Zhang and $\mathrm{Wu}, 2015$ ). These studies referred to changes in rural land use (Song and Liu, 2014) and the spatial distribution rules of rural settlements using the buffer and kernel density-analysis methods (Yin and Chen, 1995). Consequently, characteristics of spatial reconstruction and typical patterns of rural settlements have become popular research topics in academia. In the large management areas of China, which include expansive territories and diversified landforms, spatial distribution characteristics of rural settlements differ notably (Chen and Ge, 2015). These characteristics reflect the relationships between productivity, standard of living, and the local, physical geographical environment. Therefore, understanding the spatial distribution pattern of rural settlements in China is essential and fundamental for rural reconstruction (Zhou et al., 2013). The spatial distribution characteristics, scale, and diversification of rural settlements are affected by physical, geographic, and environmental factors; social and economic conditions; and historic and cultural factors (Jin, 1988). With the development of geographic information systems (GIS) and remote sensing (RS) technology, GIS have been adopted widely and successfully to study rural settlements (Liu et al., 2013a). Recent studies have combined GIS methods, which integrate fuzzy mathematics and neural networks, to study the spatial distribution of geographic phenomena (Wang and He, 2008; Yang et al., 2013a, 2013b). The expansion and spatial distribution modes of rural settlements are measured to support spatial planning by using RS and spatial analysis of the GIS (Conrad et al., 2015). The decision support system for rural environmental management should be in favor of agricultural development (Massei et al., 2014). Research methods have been updated continuously for rural settlements distribution and the dynamic mechanism of rural evolution in China.

With rapid industrialization, population density in rural areas is generally lower than before (Liu et al., 2013b; Li et al., 2014; Song and Liu, 2014). Rural spatial reconstruction is essential to effectively ensure rural sustainable development in China and achieve beautiful countryside construction (Long et al., 2016). Unfortunately, we have very little knowledge about the nationwide spatial distribution characteristics of rural settlements, the factors that affect it, and the new village-town system modes for rural space optimization and reorganization. In light of this, the current study examines the spatial distribution modes of rural settlements in China by using the Average Nearest Neighbor Ratio (Ebdon, 1985) to approximate the spatial distribution of rural settlements at the county level and examine the differences between regions. We analyzed the environmental (e.g., elevation or precipitation) and social (e.g., road access or rate of urbanization and GDP) factors, and compared the impact of the multidimensional environmental and social factors on spatial distribution characteristics of rural settlements using geographical detector research methods. Understanding the relationships between the distribution modes of rural settlements and these multidimensional impact factors at the macro level provides a basis for decision making regarding spatial optimization and reorganization of rural settlements (Liu et al., 2013a). Rebuilding the village-town system is very important for balancing urban and rural development (Liu et al., 2015; Gu et al., 2015).

\section{Materials and methods}

\subsection{Study methods}

\subsubsection{Density analysis of rural settlements}

The density of rural settlements is the number of rural settlements per unit area. It is an important indicator of the intensity of the spatial distribution of rural settlements. In this study, we calculate the density of rural settlements at the county and town levels.

\subsubsection{Spatial distribution mode of rural settlements}

Rural settlements in large-scale geospatial regions are abstracted into a series of geographical points in the study area as follows: $S_{1}=\left(x_{1}, y_{1}\right), S_{2}=\left(x_{2}, y_{2}\right), \ldots, S_{n}=\left(x_{n}, y_{n}\right)$, where $S_{i}$ is the observation event serial number (Wang and He, 2008). The spatial 
distribution modes of objects rendered into abstract geographical points have three basic distribution types: random, clustered, and uniform distributions. Although there are numerous variations in the spatial distribution of rural settlements, they can be expressed on a scale ranging from uniform to cluster distributions. Therefore, we can use quantitative methods to investigate the influence of natural, economic, and social factors on the spatial distribution of geographical points. Fig. 1 shows several possible spatial distribution modes, ranging from uniform distribution to clustered distribution.

\subsubsection{Nearest neighbor distance analysis}

The Average Nearest Neighbor Ratio ( $R$ ) helps examine the mean distances between each observed point and its nearest neighboring point. The mean is then compared to the expected value from a complete spatial randomness (CSR) pattern (Ebdon, 1985), which can be calculated using Equations (1)-(4). The first step is to calculate the average distance between each observed point and its nearest neighboring point. This is then compared to the mode of a random distribution. If the average distance to the nearest neighbor is greater than that of the average of a random distribution, then the distribution of points is considered as uniform. If the average distance to the nearest neighbor is less than the average of a random distribution mode, the points are considered as clustered (Wang and He, 2008). The calculation is as follows:

a. Calculate the distance of every point to the nearest point $\left(d_{\min }\right)$. b. Calculate the average distance of all $d_{\text {min }}$.

$\bar{d}_{\min }=\frac{1}{n} \sum_{i=1}^{n} d_{\min }\left(S_{i}\right)$

where $d_{\min }$ is the distance of each rural settlement point to its nearest neighbor, $S_{i}$ is the study event, and $n$ is the number of events.

c. The average distance to the nearest neighbor is calculated in the random distribution mode, for which expectation is $E\left(d_{\min }\right)$. The nearest $\mathrm{R}$ index is defined as

$R=\frac{\bar{d}_{\min }}{E\left(d_{\min }\right)}$,

Based on theoretical research, the average distance to the nearest neighbor in the random distribution mode relates to the area of study and the number of geographical events, which are $A$ and $n$, respectively.

$\mathrm{E}\left(\bar{d}_{\min }\right)=\frac{1}{2 \sqrt{n / A}}$

To take boundary revisions into consideration, the calculation model should be changed to
$\mathrm{E}\left(\bar{d}_{\text {min }}\right)=\frac{1}{2} \sqrt{\frac{A}{n}}+\left(0.0541+\frac{0.041}{\sqrt{n}}\right) \frac{p}{n}$

Where $p$ is the side length of the study area. If $R=1$, then rural settlements distribution is random. If $\mathrm{R}<1$, then a large number of rural settlements are close to each other in space (clustered). If $\mathrm{R}=0$, then most rural settlements are clustered in the same space (extremely clustered). If $R>1$, then the average distance to the nearest neighbor is greater than that of a random distribution mode, and thus the rural settlements in the study area are uniformly distributed. An uniform distribution mode creates an equilateral triangle that consists of three neighboring points in a homogeneous area. This also means that the space is divided into a regular hexagon in which each point is in the center of the hexagon. This is essentially the model described in Christaller's central place theory, with an average neighbor index of 2.149 (Wang and He, 2008).

\subsubsection{Geographical detector analysis}

The factors that influence the spatial distribution of rural settlements were analyzed at the county level using the geographical detector method. The model used is as follows (Wang et al., 2010; Yang et al., 2013a, 2013b):

$P_{D, U}=1-\frac{1}{n \sigma_{U}^{2}} \sum_{i=1}^{m} n_{D, i} \sigma_{U_{D, i}}^{2}$,

where $P_{D, U}$ is the power determinant of each influencing factor in a rural settlements distribution, $n_{D, i}$ is the number of sub-regional samples, $n$ is the number of samples in the entire region, and $m$ is the number of sub-regions. The variance of $\mathrm{R}$ index for the entire region's samples at the county level is denoted by $\sigma_{U}^{2}$. We used natural breaks classification of the influencing factors to divide the samples at the county level into sub-regions. The variance of the $\mathrm{R}$ index of sub-region $D_{i}$ is $\sigma_{U_{D i}}^{2}$ at the county level. If $\sigma_{U_{D i}}^{2} \neq 0$, the model will be tenable and the value used for the interval will be [0, 1]. When $P_{D, U}=0$, the spatial distribution of $\mathrm{R}$ is random. The larger the value of $P_{D, U}$, the stronger the influence of the factor of area division on the $R$ index. The distribution of rural settlements is affected by natural environmental conditions and the level of socioeconomic development. Elevation and precipitation conditions are the basic natural environmental factors. During the process of rapid urbanization, there is reconstruction in rural China, which leads to expansion of rural settlements; thus, the distribution mode of rural settlements is affected by certain economic and social factors. Gross domestic product (GDP), rate of non-agricultural industries, rural per capita net income, population density, urbanization rate, and fixed asset investment are the basic conditions for economic development. On the other hand, rural development needs to favor agricultural production conditions such as gross agricultural machinery, per capita arable land, and per grain production. Finally, geographic conditions, including distance to cities and roadways, are important factors for rural development and

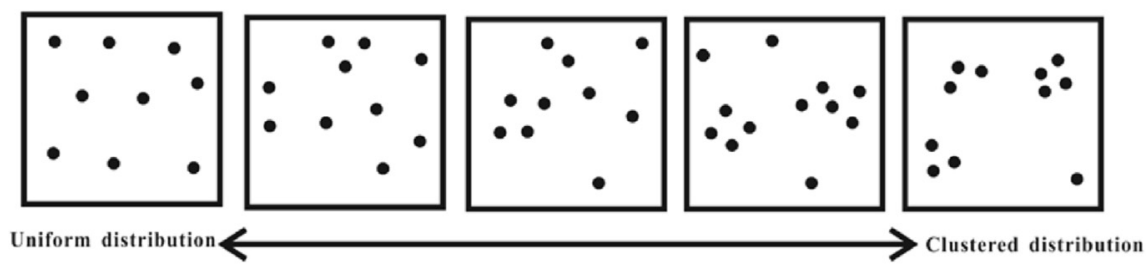

Fig. 1. Spatial distribution patterns of points (Wang and He, 2008). 
rural settlements distribution. In this study, a total of 13 impact factors were chosen including elevation $\left(x_{1}\right)$, precipitation $\left(x_{2}\right)$, urbanization rate $\left(x_{3}\right)$, per capita GDP $\left(x_{4}\right)$, rate of non-agricultural industries $\left(x_{5}\right)$, rural per capita net income $\left(x_{6}\right)$, population density $\left(x_{7}\right)$, distance to main roadway $\left(x_{8}\right)$, fixed asset investment $\left(x_{9}\right)$, distance from the center of the city $\left(x_{10}\right)$, gross agricultural machinery $\left(x_{11}\right)$, per capita arable land $\left(x_{12}\right)$, and per grain production $\left(x_{13}\right)$. These were then quantitatively identified as influencing factors for the $\mathrm{R}$ index of rural settlements distribution at the county level.

\subsection{Data sources}

China's national electronic map, with a scale of $1: 250,000$, was used to generate 3.4 million naturally distributed rural settlements points in 2012. Data on boundaries of towns, counties, and districts, as well as road vector data were sourced from The Earth Science Data Sharing Center at The Institute of Geographic Sciences and Natural Resources Research. Economic and social data at the county (district) level were sourced from the China Statistical Yearbook for Regional Economy, China County Statistical Yearbook and the statistical yearbooks of each province or municipality for 2013.

\section{Results}

\subsection{Distribution characteristics of rural settlements in China}

China has a vast territory with significant differences in regional natural resources, natural environments, and socioeconomic development. Rural settlements spaces where rural populations live and produce vary greatly in spatial distribution characteristics. At the national level, characteristics of the distribution of rural settlements in China are as follows:

(1) In the areas to the southeast of the Hu Huanyong population division line, the difference in population density between northwest and southeast China is clear (Fig. 2). Hu (1935) recognized this characteristic of population distribution in China; he determined that settlements in rural areas have higher density than those in the western regions and areas around the northern border.

(2) China has four rural settlements high-density regions (Fig. 2): (i) the contiguous area of Sichuan, Guizhou, and Chongqing (which includes the northern area of Zunyi; southwestern regions of Chongqing, Neijiang, Zigong, and Leshan; and southwestern regions of Chengdu and Suining); (ii) the contiguous area of Sichuan and Shannxi (which includes Guangyuan, Bazhong, Wanzhou district, and Dazhou); (iii) the Chang-Zhu-Tan area (which includes Huaihua, Shaoyang, Hengyang, Xiangtan, Changsha, Pingxiang, Loudi, and Yueyang), (iv) and areas in Anhui, Henan, and Hubei (which include Wuhan, Huangshi, Huanggang, Anqing, Liuan, Hefei, Chaohu, Xinyang, Xiaogan, and Zhumadian). In most of these areas, the density of rural settlements is higher than two villages per square kilometer.

(3) The central distribution of rural settlements density is significant. Among the counties studied, 1349 counties-or $46.31 \%$ - have rural settlements density between 0 and 0.5 villages per square kilometer, $87.3 \%$ have average density with less than 1.5 villages per square kilometer, and $12.7 \%$ have high density with more than 1.5 villages per square kilometer.

We evaluated the R index comprehensively by using ArcGIS10.2

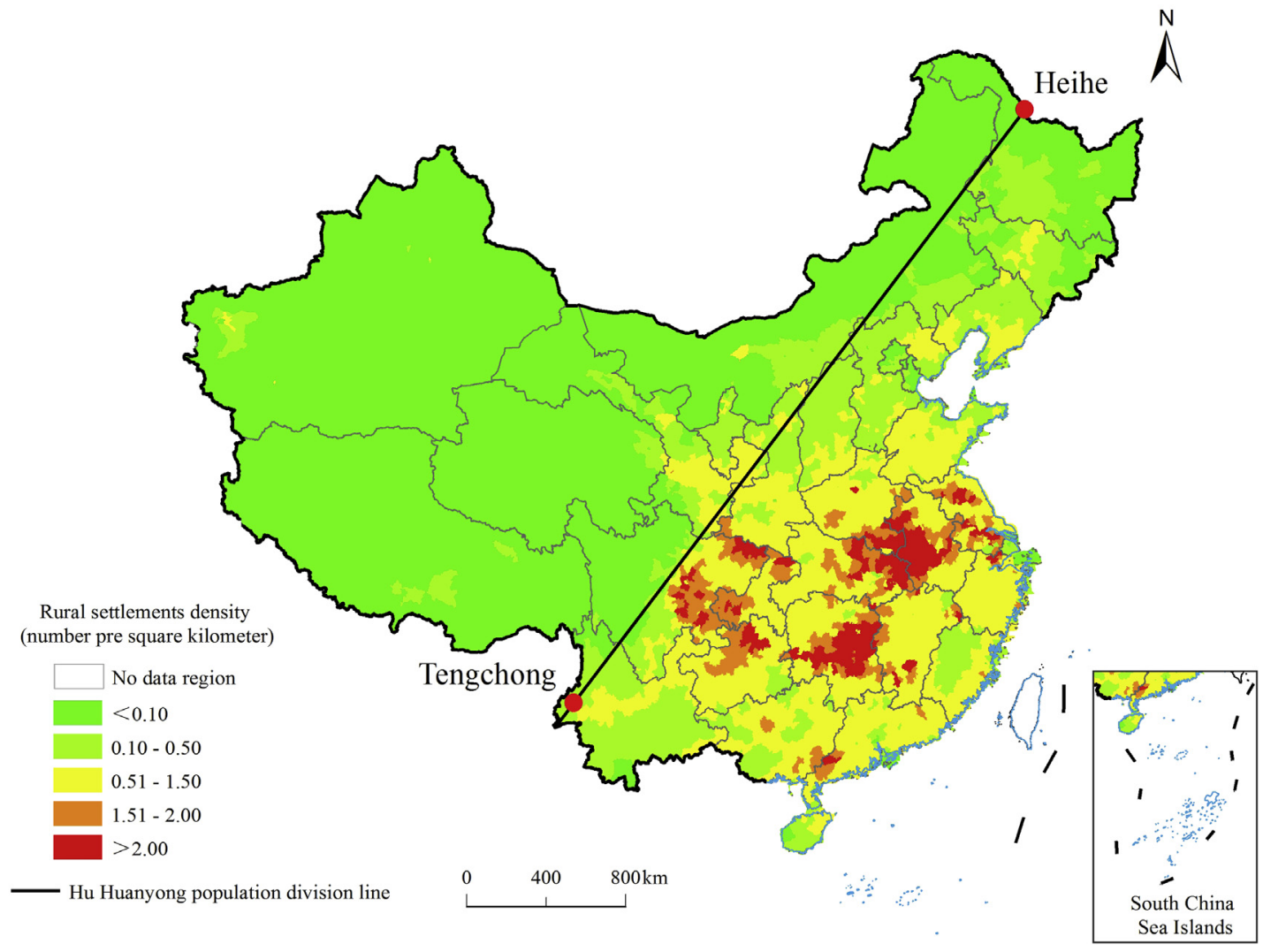

Fig. 2. Spatial distribution of rural settlements density in China. 
software (http://www.esri.com/) to calculate the average nearest neighbor distance and ideal random distribution average nearest neighbor distance among rural settlements points at the county level. This gave a quantitative description of the $\mathrm{R}$ index using the boundaries of counties and towns. Then, we applied the results of previous calculations: if $\mathrm{R}$ was less than 0.6 , it was deemed a clustered distribution, and if $\mathrm{R}$ was greater than 1.5 , it was deemed a uniform distribution. When $\mathrm{R}$ was between 0.6 and 1.5 , it was subdivided into three smaller categories: clustered-random distribution for values $0.6-0.9$, random distribution for values $0.9-1.2$, and random-discrete distribution for values 1.2-1.5 (Wang and $\mathrm{He}$, 2008). Natural rural settlements distribution patterns showed significant regional differences nationwide, which predominantly related to the following characteristics:

(1) The R index for regions to the southeast of the Hu Huanyong population division line (Fig. 3 ) is higher than the R index for the western regions and areas near the northern border. The spatial distribution of rural settlements in the eastern region tends to be random and dispersed, whereas distribution in the western regions is clustered.

(2) From the eastern margin of the Sichuan Basin to the upper reaches of the Yangtze River in the Yueyang segment, the $\mathrm{R}$ index is greater than 1.0, which means the spatial distribution of rural settlements is either dispersed or uniform. The geographical scope of $\mathrm{R}$ indexes up to 2.13 includes most of Guangyuan, Mianyang, Deyang, Suining, Neijiang, Zigong, Yibin, Luzhou, Fuling, Wanzhou district, Enshi, Zhangjiajie, Changde, Yiyang, Zhuzhou, and Xiangtan.

(3) R indexes of most agricultural areas in the eastern Loess Plateau, the North China Plain, and the Yangtze River Delta regions are between 1.00 and 1.20 , which means that the spatial distribution patterns of natural rural settlements tend to be random.

(4) In most rural settlements in western China (e.g., Tibet, western Sichuan, western Gansu, western Inner Mongolia, and Xinjiang), the $\mathrm{R}$ indexes are generally less than 0.67 , which means that rural settlements are significantly clustered. Most of these regions are sparsely populated with low density of rural settlements.

(5) The R indexes of the rural settlements in Yunnan, Guangxi, Guangdong, and the Fujian provinces are mostly between 0.6 and 0.9. The distributions of rural settlements in these regions are relatively clustered and have a clustered-random distribution pattern.

(6) Overall, the national $\mathrm{R}$ index of counties showed normal distribution with a slight skew toward the left. Among the counties studied, $61.59 \%$ had $\mathrm{R}$ index between 0.9 and 1.2 , $8.58 \%$ had $\mathrm{R}$ index of less than 0.6 , and $9.81 \%$ had $\mathrm{R}$ index more than 1.2 (Fig. 4). There was a progressive gradient from west to east: clustered $\rightarrow$ random $\rightarrow$ disperse $\rightarrow$ uniform.

This study investigated the spatial distribution of rural settlements using the R index at the town level in China. There are four high-density regions having more than two rural settlements per square kilometer and with the $\mathrm{R}$ index of generally more than 2.0 (indicating uniform distribution). To the west of the Hu Huanyong population division line, the density of rural settlements is generally less than 0.1 per square kilometer and the $\mathrm{R}$ index is less than 0.6 (Figs. 5 and 6). Because of environmental conditions and the impact of rural settlements patterns, rural settlements in sparsely populated areas maintain the spatial distribution pattern of the original villages. The density and distribution patterns of the rural settlements analyzed at the town level were same as those

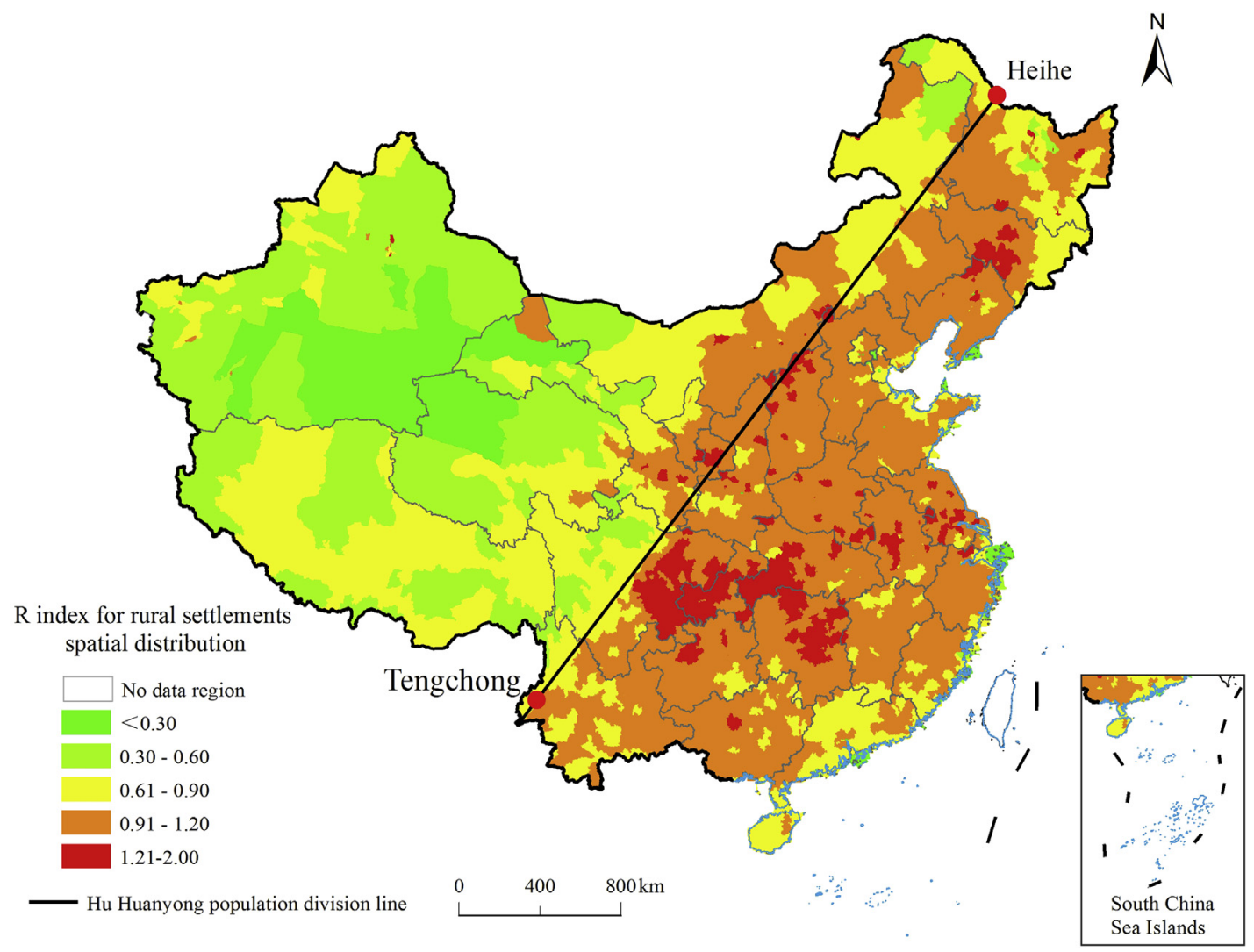

Fig. 3. $\mathrm{R}$ index for rural settlements spatial distribution in China. 


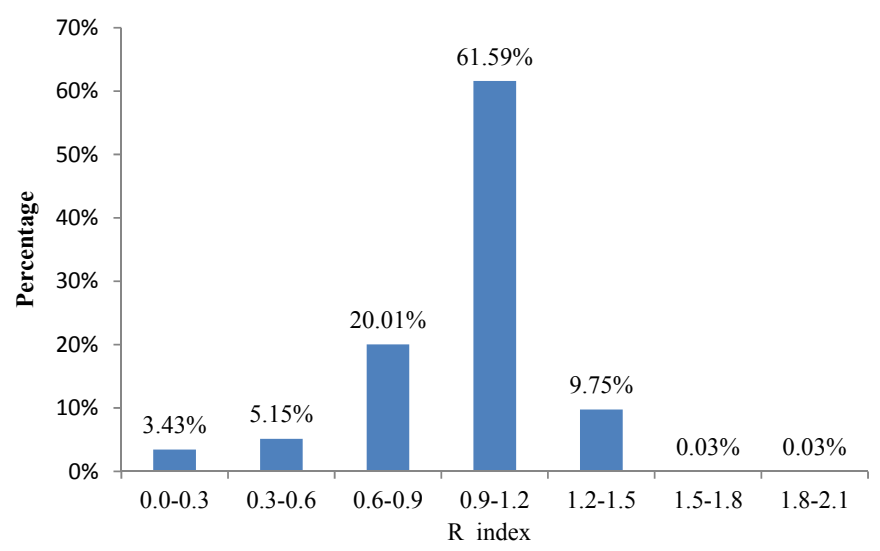

Fig. 4. Statistical classification of $\mathrm{R}$ index for spatial distribution of rural settlements in China.

analyzed at the county level. As the territory is large, the results show that the spatial distribution patterns of rural settlements tend to be relatively clustered and those of other areas tend to be randomly distributed.

\subsection{Typical distribution characteristics of rural settlements in different geographical areas}

Due to differences in physical environments, economic development levels, and social conditions, rural settlements have different distribution patterns. To investigate the characteristics of spatial distribution patterns in different geographical areas, we used the random sampling method to select typical counties in each geomorphology type region using the spatial analysis tools of ArcGIS10.2. We selected 13 representative counties randomly at the national level (Table 1). The characteristics of rural settlement distribution demonstrated by the 13 counties are as follows:

(1) Flat areas, where the density of rural settlements is concentrated, spatial distribution modes are mainly random and disperse, and average nearest neighbor distance is less than $500 \mathrm{~m}$.

(2) Highland and cold areas and desert fringes, where there is a low rural settlements density, spatial distribution modes are relatively clustered, and the average nearest neighbor distance is more than $1500 \mathrm{~m}$.

(3) The transition zone between hills and mountains, where there is high density of rural settlement areas and spatial distribution modes are largely random.

The accurate identification of distribution characteristics of rural settlements in different geographical areas provides the basis for optimized reconstruction of rural spaces.

\subsection{Driving factors of rural settlements distribution}

To quantitatively examine the relevant factors influencing rural settlements distribution at the county level, we used ArcGIS10.2 to classify every factor into high, middle, and low-grade zones using natural breaks classification. The p-values of rural settlement density, $\mathrm{R}$ index, and the nearest distance can then be calculated using the geographical detector method according to the driving factors. Table 2 presents the power determinant of each factor influencing rural settlements distribution.

Elevation and precipitation conditions can also affect the

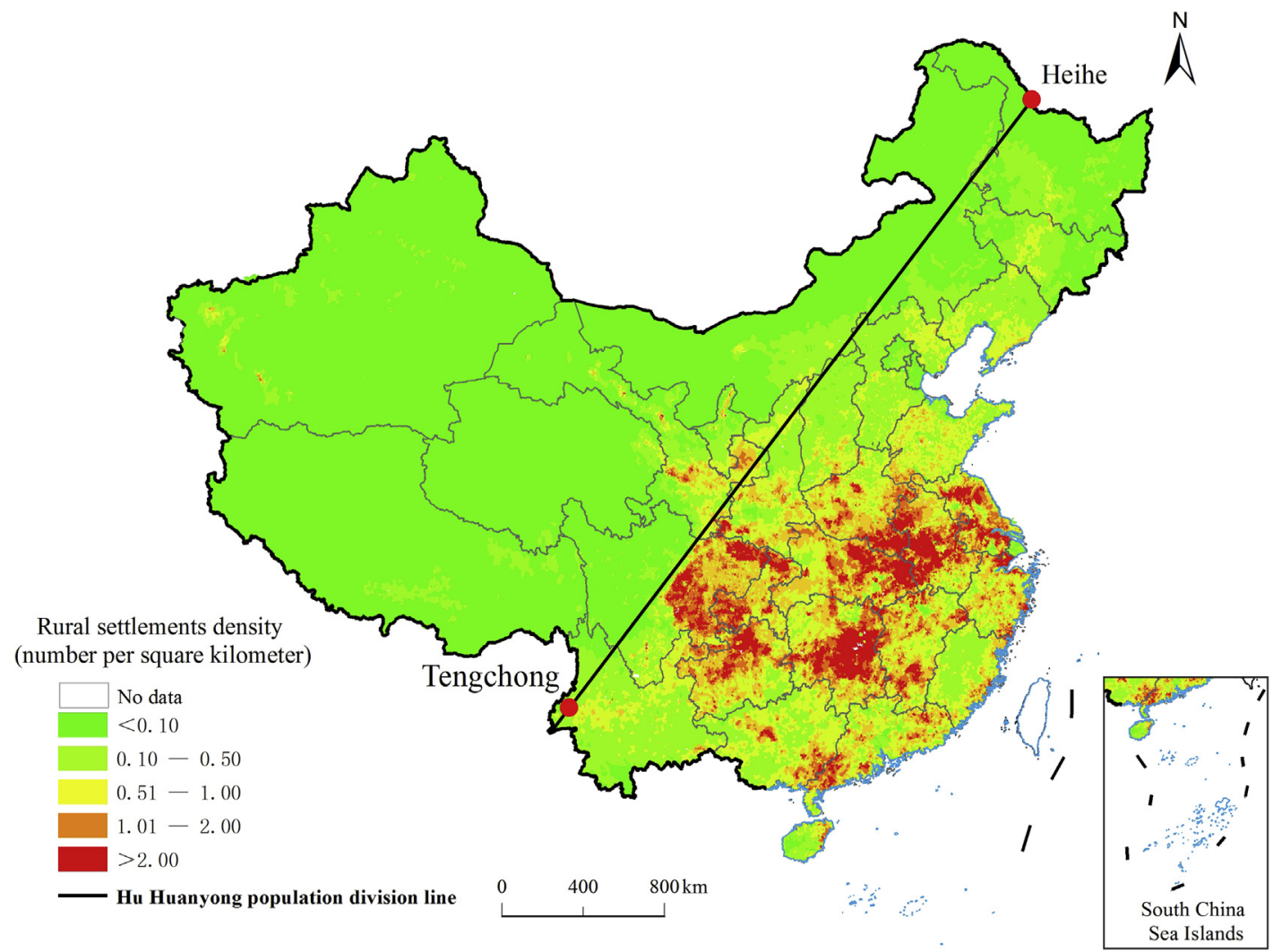

Fig. 5. Spatial distribution of rural settlements density in China at the town level. 


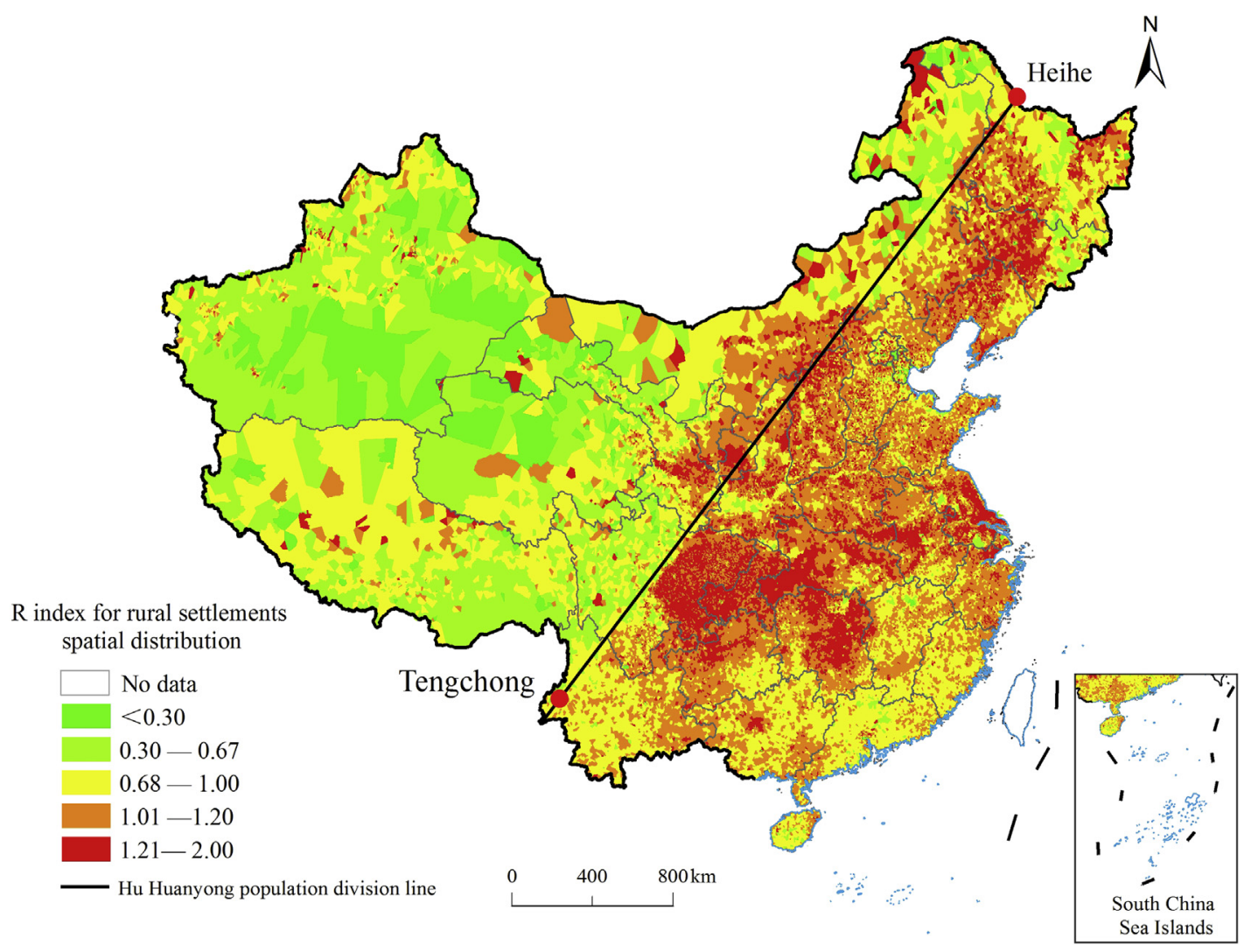

Fig. 6. Distribution of $\mathrm{R}$ indexes for rural settlements in China at the town level.

Table 1

Spatial distribution characteristics of rural settlements in 13 typical geographical counties.

\begin{tabular}{|c|c|c|c|c|c|c|c|c|}
\hline county & $\begin{array}{l}\text { Area } \\
\left(\mathrm{km}^{2}\right)\end{array}$ & $\begin{array}{l}\text { Density (village/ } \\
\mathrm{km}^{2} \text { ) }\end{array}$ & Number & $\begin{array}{l}\text { Nearest distance } \\
(\mathrm{m})\end{array}$ & $\begin{array}{l}\mathrm{Cv} \text { of nearest } \\
\text { distance }\end{array}$ & $\begin{array}{l}\mathrm{R} \\
\text { Index }\end{array}$ & $\begin{array}{l}\text { Distributed } \\
\text { pattern }\end{array}$ & Region \\
\hline Wanzhou & 3452.79 & 1.19 & 4099 & 557.45 & 0.38 & 1.21 & Random & Hilly region \\
\hline Jiuzaigou & 5276.77 & 0.05 & 257 & 1658.82 & 0.76 & 0.73 & Clustered & High mountain, gorge \\
\hline Hoboksar & 28791.84 & 0.01 & 293 & 2572.92 & 0.95 & 0.52 & Clustered & The edge of drought basin \\
\hline Dangxiong & 10247.41 & 0.04 & 395 & 1617.45 & 0.66 & 0.64 & Clustered & Highland and cold areas \\
\hline Gaoyou & 1968.00 & 1.22 & 2405 & 495.35 & 0.35 & 1.10 & Random & Yangtze River Delta Plain \\
\hline Wuning & 3508.25 & 1.03 & 3603 & 423.59 & 0.54 & 0.86 & Clustered & Mountain, hilly region \\
\hline Sunite & 22685.63 & 0.01 & 178 & 4485.87 & 0.92 & 0.79 & Clustered & Erosional plateau \\
\hline Yingde & 5631.74 & 0.80 & 4531 & 463.63 & 0.65 & 0.83 & Slightly clustered & Mountain area, basin \\
\hline Renqiu & 1019.58 & 0.27 & 278 & 839.16 & 0.63 & 0.88 & Slightly clustered & Plain \\
\hline Gushi & 2950.13 & 2.43 & 7172 & 406.51 & 0.34 & 1.27 & Dispersed & Transition zone between hills and plains \\
\hline Qingyuan & 3936.70 & 0.21 & 812 & 1159.47 & 0.50 & 1.05 & Random & $\begin{array}{l}\text { Mountain areas and hilly region in northeast } \\
\text { China }\end{array}$ \\
\hline Ninglang & 6029.69 & 0.18 & 1081 & 1130.52 & 0.59 & 0.86 & Clustered & Yunnan-Guizhou Plateau \\
\hline Qiemo & 137632.04 & 0.01 & 226 & 3629.41 & 2.28 & 0.29 & Clustered & Fringes of the desert \\
\hline
\end{tabular}

Coefficient of variation $(\mathrm{Cv})$ is the ratio of standard deviation and average which reflects differences.

Table 2

The p-value of factors affecting rural settlements distribution in China.

\begin{tabular}{|c|c|c|c|c|c|c|c|c|c|c|c|c|c|}
\hline P-value & $x_{1}$ & $x_{2}$ & $x_{3}$ & $x_{4}$ & $x_{5}$ & $x_{6}$ & $x_{7}$ & $x_{8}$ & $x_{9}$ & $x_{10}$ & $x_{11}$ & $x_{12}$ & $x_{13}$ \\
\hline Density & 0.49 & 0.64 & 0.59 & 0.41 & 0.40 & 0.40 & 0.57 & 0.51 & 0.43 & 0.48 & 0.44 & 0.38 & 0.41 \\
\hline $\mathrm{R}$ index & 0.65 & 0.53 & 0.60 & 0.42 & 0.41 & 0.58 & 0.57 & 0.56 & 0.45 & 0.53 & 0.51 & 0.41 & 0.42 \\
\hline Nearest distance & 0.60 & 0.81 & 0.70 & 0.59 & 0.44 & 0.61 & 0.70 & 0.80 & 0.47 & 0.83 & 0.57 & 0.63 & 0.68 \\
\hline
\end{tabular}

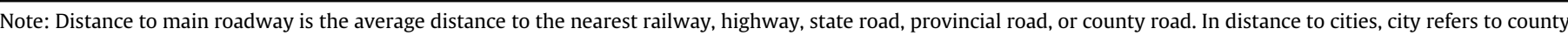

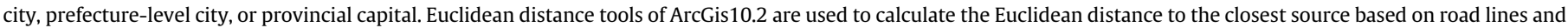
urban point data for each cell.

distribution of rural settlements; the p-values of elevation and precipitation for rural settlement density were 0.49 and 0.64 , respectively. Differences in modes of production and leading industries will have varying influences on the distribution of rural settlements. P-values of urbanization and non-agricultural income to rural settlements density, the $\mathrm{R}$ index of rural settlements 
distribution, and the nearest distance among rural settlements were all found to be more than 0.40 at the county level in China. Traffic conditions are another main factor affecting the spatial distribution of towns and rural settlements. In 2012, the p-values of average distance to main roadway to rural settlements density, the $\mathrm{R}$ index of rural settlements distribution, and nearest neighbor distance of rural settlements were $0.51,0.56$, and 0.80 , respectively, at the county level in China. Thus, the development of external transport has direct impact on the economic prosperity of settlements. The distribution of population plays a significant role in the formation and development of rural settlements distribution. The p-values for the relationship between the geographical factors of population density to rural settlements distribution density, the $R$ index of rural settlements, and nearest neighbor distance among rural settlements points were $0.57,0.57$, and 0.70 , respectively.

\section{Reconstructing a new village-town system}

The village-town hierarchical structure (with basic villages relying on central towns for extended services) of rural systems is visible in the patterns of optimization and spatial planning. The village-town system describes the general designations of villages and towns: rural settlements based on agricultural economies serving regional agricultural producers and residences. There are four levels in the hierarchical structure of villages and towns: natural or basic villages, central villages, towns, and townships. Natural villages form naturally, have populations ranging from dozens to hundreds, and may contain one to several groups of villages (Bai et al., 2014). Residents in natural villages mainly work in agriculture. Natural villages are the most basic settlements form in the village-town classification system with simple living facilities. Central villages are host to rural administrative organs, with several living facilities and infrastructure that have the ability to provide limited public services for rural residents. Most towns represent the economic center of rural regions and include settlements based on markets. As townships are the political, economic, cultural, and residential service centers of rural regions, their governments have administrative power. Taking the natural conditions of different regions into consideration, spatial distribution patterns can have a radially balanced, central place distribution mode; a radially imbalanced distribution mode; a multicore central place distribution mode; or a corridor balanced or imbalanced distribution mode.

\subsection{Radially balanced, central place distribution mode}

On the plains or in low-altitude hilly regions where the terrain is flat and natural substrates are common, rural settlements spatial distribution is usually dispersed (Yang et al., 2015b; Ge, 2010). According to the central place theory, rural optimization and reorganization should achieve a spatial organizational structure that includes towns, central villages, and basic villages (Fig. 7-a). Basic services and public infrastructure of relatively high standards should be provided in central villages (Fig. 7-a) so that with balanced distribution, each basic village can enjoy equal services from central villages and towns.

\subsection{Radially imbalanced distribution mode}

In the transitional zone between plains and mountainous areas, spatial distribution of rural settlements is clustered. Thus, when planning rural spatial distribution, central villages should be located below the mountains where they can influence several basic villages on the plains. The terrain obstructs and limits the patterns of basic and central villages in mountainous areas; therefore, to optimize public service facilities from central villages and towns, basic villages should radially surround the central villages (Fig. 7-b).

\subsection{Multicore central place distribution mode}

On the plains or in hilly areas, villages are distributed at dispersed points, whereas the space associated with town areas is long and narrow. Using the central place theory to optimize and reorganize rural spaces will create the best results for central and basic villages, with towns, industrial parks, or markets groups as
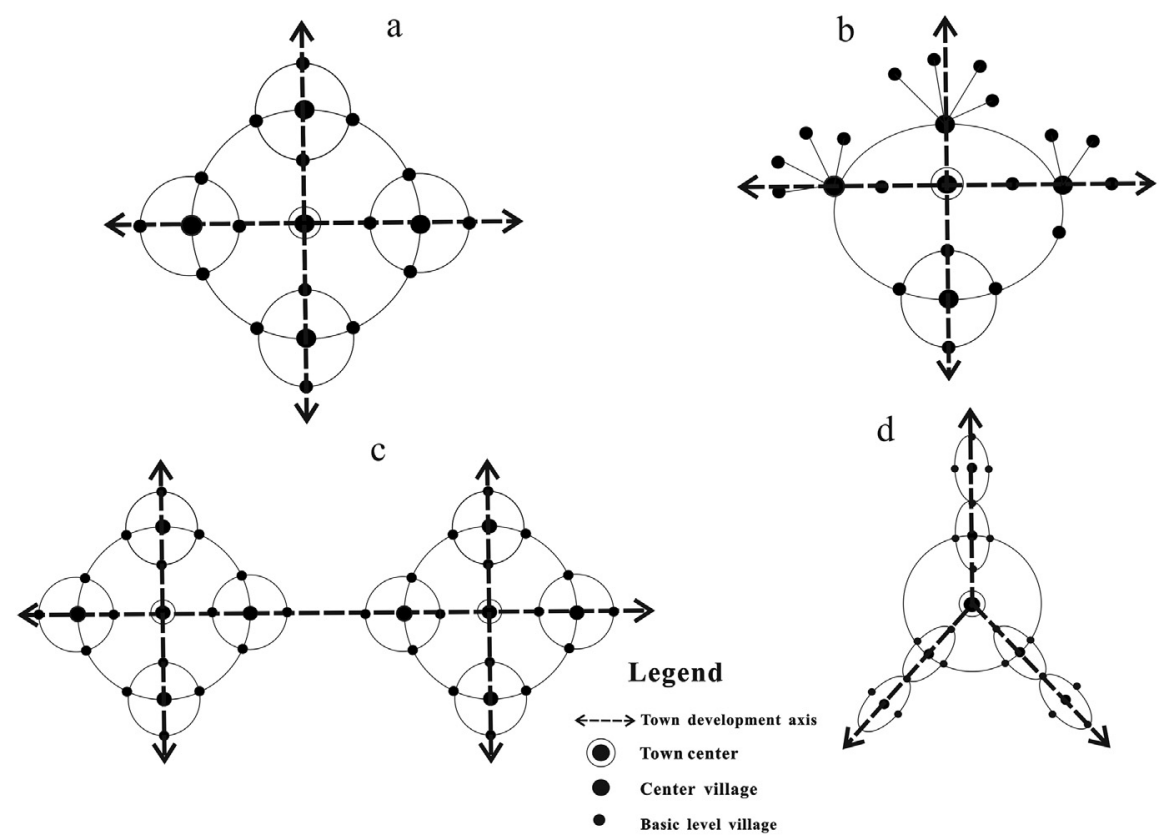

Fig. 7. Restructuring plans for rural settlement space optimization. 
their cores (Fig. 7-c).

\subsection{Corridor balanced and imbalanced distribution mode}

In this mode, rural settlements distribution is dispersed and zonal. Spatial patterns of central and basic villages are directed and cultivated along the axes of roads in mountainous regions or river banks. Central villages are located in the center of the distribution pattern, whereas basic villages are distributed along mountains or river basins. This distribution pattern gradually becomes moniliform, forming a balanced corridor. The central village is located at the center of the corridor, where it can reach the maximum service radius and have great influence on basic villages (Fig. 7-d). In some rural settlements distribution conditions, central villages are located on mountain passes and basic villages are located on the mountains behind central villages. Thus, central villages have optimal locations and their influence on basic villages is imbalanced.

Although rural distribution modes for spatial optimization and reorganization can be classified into the four categories mentioned above, the relationships between central and basic villages are complex because of a combination of regional features. Thus, we should consider mixed distribution modes that combine centrality and production specificities.

\section{Discussion}

\subsection{Regional differences in rural settlements distribution in China}

In this study, we have shown that regional differences in the characteristics and modes of spatial distribution of rural settlements are apparent in China. Overall, the spatial distribution density of rural settlements in regions to the east and southeast of the Hu Huanyong population division line is higher than those to the west or north. China has four high-density rural settlement areas, including the contiguous area of Sichuan-Guizhou-Chongqing, the contiguous area of Sichuan-Shaanxi, the Chang-Zhu-Tan area, and areas of Anhui-Henan-Hubei. Population quantity, livable environment, and other factors affect the development of villages and expansion of rural settlements (Long and Li, 2012; Song and Liu, 2014). The distribution of population plays a significant role in the formation and development of rural settlements distribution (Yang et al., 2015a). Rural settlements density is higher and the process of urbanization is more rapid in densely populated areas (Zhou et al., 2013). In contrast, rural settlements density is lower in sparsely populated areas, and further development is limited by low population (Li et al., 2014). Generally, developed areas have a higher population density, as the long history of immigration and development has created a positive feedback effect (Yang et al., 2012). These high-density, rural, residential areas belong to traditional Chinese agricultural regions, with abundant cultivated land resources and favorable environment for agricultural production (Yang et al., 2013a, 2013b). However, the rural settlements spatial distribution density of Tibet, Xinjiang, Qinghai, Inner Mongolia, and western parts of southwest China are all relatively low because of the limited environmental suitability of rural settlements areas (Liu and Yang, 2012).

\subsection{Regional differences of the rural settlements distribution modes in China}

We have shown that rural settlements density is directly related to the spatial distribution modes of rural areas. Figs. 2, 3, 6 and 7 show that the rural settlements spatial distribution modes of high-density areas are random and dispersed, whereas those of low-density areas are clustered. Rural settlements tend to be less clustered in areas with high population densities, such as those on plains along rivers, low mountains, hills, gentle slopes, or edges of hills (Yang et al., 2015a, 2015b). All rural settlements in these regions are close to each other because of high population density (Zhou et al., 2013), collectively forming four high-density regions of disperse rural settlements. These densely populated areas have a variety of natural resources (Feng and Li, 2007). Therefore, their future developmental direction and the mode of optimization of rural settlements spatial patterns should be considered independently (Liu et al., 2013a, 2013b). In western areas of China (e.g., Tibet, Sinkaing, Qinghai, Inner Mongolia, and western parts of the southwest region), the density of rural settlements tends to be low. Restrictive conditions (e.g., the form of rural settlements and harsh living conditions) led to this vast area being sparsely populated with low rural settlements density (Guo et al., 2012).

Different regions have different characteristics of rural settlements spatial distribution. We have selected 13 counties-cases with typical regional characteristics of the Chinese landform-to reveal their rural settlements spatial distribution modes. Spatial distribution of rural settlements in plain areas is dense, with highdensity distribution forms (mainly random and dispersed with neighboring villages being close together). Rural settlements spatial distribution density of highland areas, cold areas, and desert margins is very low. This results in long distances between neighboring villages and aggregated rural settlements spatial distribution. Spatial distribution density of hilly and mountainous areas is relatively high, and the spatial distribution mode of these regions tends to be random.

\subsection{Influence mechanism of rural settlements distribution in China}

In this study, we have illustrated the driving factors of rural settlements distribution modes in China. The characteristics of rural settlements distribution reflect the condition of the natural environment and the level of regional socioeconomic development (Feng and Li, 2007). Therefore, although rural settlements distribution is affected by many factors, these two are the primary influencers (Gude et al., 2006). Therefore, we have chosen 13 factors of driving power for the spatial distribution of rural settlements at the county level in China.

Factors that influence spatial distribution of rural settlements were analyzed using the geographical detector method. As seen in Table 2, rural settlements distribution is affected by traditional factors as well as economic development. Elevation and the condition of water resources are basic natural factors that also affect the distribution of rural settlements (Guo et al., 2012; Yang et al., 2015c). Rural settlements are denser in plains, whereas they are sparser in mountainous areas. Majority of the villages are scattered throughout areas of the countryside that are rich in water and grass or in places that have convenient transportation (Yang et al., 2015b). In traditional agricultural areas such as plains, uniform distribution with small villages is the characteristic of the traditional peasant economy. Although traditional factors still play a significant role, the economy's influence is becoming increasingly pronounced (Liu et al., 2013a, 2013b). Developed areas with nonagricultural industries have increased in population concentration, and villages have conglomerated into larger settlements (Liu et al., 2014). Different modes of production and leading industries have varying influences on the distribution of rural settlements ( $\mathrm{Li}$ and $\mathrm{Li}, 2009$ ). In traditional economic conditions, the leading factors that affect spatial distribution are the range of activities and social ties between rural settlements (Zhou et al., 2013).

Traffic conditions are another important factor that affects the spatial distribution of towns and rural settlements (Xi et al., 2015). 
Larger villages are often located in areas that can be reached via well-maintained roads (Yang et al., 2015b). Thus, the development of external transport has direct impact on the economic prosperity of settlements, increasing the closeness of the economic relationships between neighboring areas. Well-developed transportation systems can promote the exchange of goods, culture, and technology, thereby accelerating the development of production and increasing the proportion of the population concentrated in towns (Zhou et al., 2013). Meanwhile, non-agricultural industries, economic development, and agricultural modernization exert strong influences on the spatial forms and distribution modes of rural living and production space.

\subsection{Background to reconstructing the village-town system}

During the transformation of the rural economy, traditional natural and economic restrictions play less important roles in the distribution of rural settlements (Liu and Yang, 2015; Long et al., 2016). In contrast, industrialization, urbanization, and agricultural modernization have become the new driving force for rural space optimization (Yang et al., 2015a). Nationwide, most rural settlements are distributed in random or dispersed patterns. However, the comprehensive structure and functions of village-town systems have not been developed yet. Under the influence of numerous factors, rural economic transformation has strong impact on economic modes and social networks. Thus, the priority is to rebuild the village-town system (Liu and Yang, 2012; Yang et al., 2012, 2015c). Small towns are important drivers for China's urbanization and rural transformation development (Gu et al., 2015).

Rural economies are rapidly changing, owing to the increase in non-agricultural populations. Although agriculture is no longer the leading driver for rural economic development, it remains a key influencing industry. Urbanization has changed the factors that affected population distribution for thousands of years. As the dominant forces of the rural economy are rapidly transforming, the agglomeration of non-agricultural labor forces is becoming more obvious. Now, optimization of future distribution patterns of towns and villages should be achieved by concentrating the supply of public facilities and cultural services in townships, improving facilities and infrastructure in central villages, promoting tertiary industries, and aggregating rural populations (Liu et al., 2015). The development of public facilities and infrastructure in central villages will have a broad-scale effect, and the current naturally distributed villages will become incorporated into centralized villages. The overall planning of the village-town system requires comprehensive evaluation of the economic development, transportation, location, population, and current situation of construction of each town in order to optimize the spatial structure of towns and villages. Transportation, industry, production mode, and public facilities are crucial forces that should be integrated in rural regions to ensure substantial change; they are also the main characteristics differentiating modern rural regions from traditional ones and the main factors affecting future optimization of spatial distribution in towns and villages. A spatial structure of central-basic village system-based on the village-town system-that relies on a central township will be an optimized structure for the reorganization of rural space (Ge, 2010). Different areas should adopt different rural settlements distribution patterns (e.g., radially balanced distribution mode, radially imbalanced distribution mode, multicore distribution mode, corridor balanced mode, and mixed distribution mode) as suited to their local environmental and geographic conditions.

\subsection{Research prospects and future work}

In this study, we have described the spatial distribution density and spatial mode characteristics of rural settlements in China, their influencing factors, and four village-town system modes for rural space optimization and reorganization. Further analysis will be required to understand the micro-morphological landscape forms of rural settlements, types of village-space reconstruction, social behavior of rural individuals that results in rural settlements development (Daskon, 2010), relationships between rural settlements, sociocultural and Internet-era backgrounds of rural settlements, reconstruction of the rural-market network system, construction of living service circles with town cores to explore reconstruction for production, living and ecological spaces, sociocultural heritage, protection theories, and practice studies. These are the core fields of Chinese rural transformation and reconstruction in the process of globalization (Yang et al., 2015c). We will study the regional variations of different ethnic regions, each major river-basin unit (e.g., the Yangtze River and the Yellow River, including both upstream and downstream regions), coastal areas, urban agglomeration (metropolitan) areas, and other areas with specific economic, social, or cultural characteristics. Based on the typical regional characteristics and centralization of basic services, this study has provided an overview of the modes of the spatial structure of villages and towns. However, because of the large geographical differences between Chinese territories (e.g., regional differences in natural environments, economic development, social characteristics, and cultural characteristics) further studies are required to investigate the spatial distribution patterns of villages and towns.

\section{Conclusions}

In this study, the Average Nearest Neighbor Distance (R) index and the geographical detector method were integrated to identify rural settlements distribution modes and their driving factors. The geographical detector method is often used to research the influence mechanism of the spatial distribution of medical and health care within a physical geography; we have applied this method to rural geography.

We have shown that China has varied rural settlements distribution, such as clustered, random, and uniform discrete, with significant regional differences. In areas to the southeast of the $\mathrm{Hu}$ Huanyong populationdivision line, the difference in population density between northwest and southeast China was clear; here, rural settlements had higher density than those in the western region or areas around the northern border. Rural settlements were denser in southeastern regions than in northwestern regions. China has four high-density rural settlements areas: the contiguous area of Sichuan-Guizhou-Chongqing, the contiguous area of SichuanShaanxi, the Chang-Zhu-Tan area, and areas of Anhui-HenanHubei. In regions such as plains, the spatial distribution of rural settlements was denser and the rural settlements distribution modes were mainly random and disperse. In regions such as cold alpine areas and desert fringes, the rural settlements density was low and the distribution modes were mainly clustered. In the transition zone between hills and mountains, the density of rural settlements was high and the spatial distribution mode was mainly random. Rural settlements distribution was influenced by tradition and the economy, with economic development becoming increasingly influential.

We revealed the driving factors of rural settlements distribution, which included physical geographical factors and socioeconomic conditions. Traffic conditions are a main factor affecting the spatial distribution of towns and rural settlements. Elevation and precipitation conditions can also affect the distribution of rural settlements; the p-values of elevation and precipitation for rural settlements density were 0.49 and 0.64 , respectively. In 2012 , the p- 
values of the distance to main roads to rural settlements density, the $\mathrm{R}$ index of rural settlements distribution, and the nearest neighbor distance of rural settlements were $0.51,0.56$, and 0.80 , respectively, at the county scale in China. Thus, the development of external transport has direct impact on the economic prosperity of rural settlements. Other economic factors, environmental conditions, agricultural industry structure, agricultural production conditions, and grain production also affect rural settlements distribution.

Because of rapid industrialization, the population density in rural areas is generally lower; spatial optimized reconstruction of rural settlements is recognized as an important part of rural sustainable development. Multiple distribution patterns should be used to reconstruct rural spaces in different geographical areas. In this study, we presented four typical patterns of restructuring plans for the space optimization of rural settlements; these are radially balanced, central land distribution mode, radially imbalanced distribution mode, multicore central place distribution mode, and corridor balanced and imbalanced distribution modes.

\section{Acknowledgements}

This work was supported by the National nature Science Foundation of China (Grant No. 41401190) and the Fundamental Research Funds for the Central Universities (No. 15lgpy34). The insightful and constructive comments and suggestions from both the anonymous reviewer and the editor Professor Michael Woods are greatly appreciated.

\section{References}

Ali, A.M.S., 2007. Population pressure, agricultural intensification and changes in rural systems in Bangladesh. Geoforum 38, 720-738.

Bai, X.M., Shi, P.J., Liu, Y.S., 2014. Realizing China's urban dream. Nature 509, $158-160$.

Cloke, P., 1979. Key Rural Settlements in Rural Areas. Methuen \& Co. Ltd, London.

Chen, Y.H., Ge, Y., 2015. Spatial point pattern analysis on the villages in China's poverty-stricken areas. Procedia Environ. Sci. 27, 98-105.

Conrad, C., Rudloff, M., Abdullaev, I., et al., 2015. Measuring rural settlement expansion in Uzbekistan using remote sensing to support spatial planning. Appl. Geogr. 62, 29-43.

Daskon, C.D., 2010. Cultural resilience-the roles of cultural traditions in sustaining rural livelihoods: a case study from rural Kandyan villages in Central Sri Lanka. Sutainability 2, 1080-1100.

DeMarco, M., Matusitz, J., 2011. The impact of central-place theory on Wal-Mart. J. Hum. Behav. Soc. Environ. 21 (2), 130-141.

Dumreicher, H., 2008. Chinese villages and their sustainable future: the European Union-China-Research Project "SUCCESS". J. Environ. Manag. 87, 204-215.

Ebdon, D., 1985. Statistics in Geography. Basil Blackwell, Oxford.

Feng, W.L., Li, A.L., 2007. Spatial pattern of rural settlements in the upper reaches of the Minjiang River. J. Mt. Sci. 4 (2), 146-154.

Fink, M., Lang, R., Harms, R., 2013. Local responses to global technological change: contrasting restructuring practices in two rural communities in Austria. Technol. Forecast. Soc. Change 80, 243-252.

Gu, C., Li, Y., Han, S.S., 2015. Development and transition of small towns in rural China. Habitat Int. 50, 110-119.

Guo, X.D., Zhang, Q.Y., Ma, L.B., 2012. Analysis of the spatial distribution character and its influence factors of rural settlement in transition-region between mountain and hilly. Econ. Geogr. 32 (10), 114-120 (in Chinese).

Ge, D.D., 2010. The System and Mode of Rural Planning in China: Technology and Strategy of the New Rural Construction. M. Southeast University Press, Nanjing (in Chinese).

Gude, P.H., Hansen, A.J., Rasker, R., et al., 2006. Rates and drivers of rural residential development in the Greater Yellowstone. Landsc. Urban Plan. 77, 131-151.

Holmes, J., 2008. Policy issues concerning rural settlement in Australia's pastoral zone. Aust. Geogr. Stud. 23 (1), 3-27.

Han, F., Cai, J.M., 2011. The evolution and reconstruction of per-urban rural habitat in China. Acta Geogr. Sin. 30 (7), 1271-1284 (in Chinese).

Hill, M., 2003. Rural Settlement and the Urban Impact on the Countryside. Hodder \& Stoughton, London, pp. 58-72.

Hu, H.Y., 1935. Essays on China's population distribution. Acta Geogr. Sin. 2 (1), 33-74 (in Chinese).

Huang, Z.Z., 2000. The Peasant Family and Rural Development in the Yangtze Delta. Zhonghua Book Company, Beijing (in Chinese).

Jin, Q.M., 1988. The history and current trends of research on rural settlement geography in China. Acta Geogr. Sin. 43 (4), 311-317 (in Chinese).

Jin, Q.M., Dong, X., Zhang, X.L., 1990. Rural Geography. Jiangsu Education Press, Jiangsu.

Jones, E.E., 2010. An analysis of factors influencing sixteenth and seventeenth century Haudenosaunee (Iroquois) settlement locations. J. Anthropol. Archaeol. 29, $1-14$.

Li, J., Li, X.J., 2008. A review on location of the rural settlement. Hum. Geogr. 23 (4), 23-27 (in Chinese).

Li, J., Li, X.J., 2009. Study on the effect factors and distribution changes of rural residential under the multiple regional environment: a case study of Gongyi city in Henan province. Resour. Sci. 31 (7), 1195-1204 (in Chinese).

Liu, Y.S., Liu, Y., Zhai, R.X., 2009. Geographical research and optimizing practice of rural hollowing in China. Acta Geogr. Sin. 64 (10), 1193-1202 (in Chinese).

Liu, Y.S., Liu, Y., Chen, Y.F., et al., 2010. The process and driving forces of rural hollowing in China under rapid urbanization. J. Geogr. Sci. 20 (6), 876-888.

Liu, Y.S., Yang, R., 2012. The spatial characteristics and formation mechanism of the county urbanization in China. Acta Geogr. Sin. 67 (8), 1011-1020 (in Chinese).

Liu, Y.S., Yang, R., Li, Y.H., 2013a. Potential of land consolidation of hollowed villages under different urbanization scenarios in China. J. Geogr. Sci. 23, 503-512.

Liu, Y.S., Lu, S.S., Chen, Y.F., 2013b. Spatio-temporal change of urban-rural equalized development patterns in China and its driving factors. J. Rural. Stud. 32, 320-330.

Liu, Y.S., Yang, R., Long, H.L., 2014. Implications of land-use change in rural China: a case study of Yucheng, Shandong province. Land Use Policy 40, 111-118.

Liu, Y.S., Yang, R., 2015. The spatial pattern measure of urban-rural development transformation in the Bohai Rim region in China. Acta Geogr. Sin. 70 (2), $248-256$

Liu, Y.S., Chen, C., Li, Y.R., 2015. Differentiation regularity of urban-rural equalized development at prefecture-level city in China. J. Geogr. Sci. 25 (9), 1075-1088.

Li, Y.R., Long, H.L., Liu, Y.S., 2015. Spatio-temporal pattern of China's rural development: a rurality index perspective. J. Rural. Stud. 38, 12-26.

Li, Y.R., Liu, Y.S., Long, H.L., et al., 2014. Community-based rural residential land consolidation and allocation can help to revitalize hollowed villages in traditional agricultural areas of China: evidence from Dancheng County, Henan Province. Land Use Policy 39, 188-198.

Long, H.L., Liu, Y.S., Wu, X.Q., 2009a. Spatio-temporal dynamic patterns of farmland and rural settlements in $\mathrm{Su}-\mathrm{Xi}-$ Chang region: implications for building a new countryside in coastal China. Land Use Policy 26 (2), 322-333.

Long, H.L., Liu, Y.S., Zou, J., 2009b. Assessment of rural development types and their rurality in eastern coastal China. Acta Geogr. Sin. 64 (4), 426-434 (in Chinese).

Long, H.L., Li, T.T., 2012. The coupling characteristics and mechanism of farmland and rural housing land transition in China. J. Geogr. Sci. 22 (3), 548-562.

Long, H.L., Li, Y.R., Liu, Y.S., et al., 2012. Accelerated restructuring in rural China fueled by 'increasing vs. decreasing balance' land-use policy for dealing with hollowed villages. Land Use Policy 29 (1), 11-22.

Long, H.L., Tu, S.S., Ge, D., et al., 2016. The allocation and management of critical resources in rural China under restructuring: problems and prospects. J. Rural Stud. http://dx.doi.org/10.1016/j.jrurstud.2016. 03.011.

Marc, A., 2004. Landscape change and the urbanization process in Europe. Landsc. Urban Plan. 67 (3), 9-29.

Marsden, T., Sonnino, R., 2008. Rural development and the regional state: denying multifunctional agriculture in the UK. J. Rural. Stud. 24, 422-431.

Massei, G., Rocchi, L., Paolotti, L., et al., 2014. Decision supportsystems for environmental management: a case study on wastewater from agriculture. J. Environ. Manag. 146, 491-504.

Ottomano Palmisano, G., Govindan, K., Loisi, R.V., et al., 2016. Greenways for rural sustainable development: an integration between geographic information systems and group analytic hierarchy process. Land Use Policy 50, 429-440.

Paul, O., 2009. Rural settlement and economic development in Southern Italy: Troia and its contado. J. Mediev. Hist. 31 (4), 327-345.

Ripley, B.D., 1977. Modelling spatial patterns. R. Stat. Soc. 39, 172-212.

Robinson, P.S., 2003. Implications of rural settlement patterns for development: a historical case study in Qaukeni, Eastern Cape. S. Afr. Dev. South. Afr. 20, 405-421.

Su, S., Zhang, Q., Zhang, Z., et al., 2011. Rural settlement expansion and paddy soil loss across an ex-urbanizing watershed in eastern coastal China during market transition. Reg. Environ. Change 11 (3), 651-662.

Shan, Y.B., Ma, X.D., Qiu, F.D., 2012. Distribution patterns characteristics and type classification of the rural settlements in central Jiangsu province. Sci. Geogr. Sin. 32 (11), 1340-1347 (in Chinese).

Song, W., Liu, M., 2014. Assessment of decoupling between rural settlement area and rural population in China. Land Use Policy 39, 331-341.

Tian, G.J., Yang, Z.F., Zhang, Y.Q., 2007. The spatio-temporal dynamic pattern of rural residential in China in the 1990s using Landsat TM images and GIS. Environ. Manag. 40, 803-813.

Terry, M., 1996. Rural Geography Trend Report: the social and political bases of rural restructuring. Prog. Hum. Geogr. 20 (2), 246-258.

Tan, M.H., Li, X.B., 2013. The changing settlements in rural areas under urban pressure in China: patterns, driving forces and policy implications. Landsc. Urban Plan. 120, 170-177.

William, S., 1964. Marketing and social structure in rural China. J. Asian Stud. 24 (1), 3-43.

Wang, J.F., Li, X.H., Christakos, G., 2010. Geographical detectors-based health risk assessment and its application in the neural tube defects study of the He shun Region, China. Int. J. Geogr. Inf. Sci. 24 (1), 107-127. 
Wang, Y.F., He, H.L., 2008. Spatial Data Analysis Method. M. Science Press, Beijing. Woods, M., 2005. Rural Geography: Processes, Responses and Experiences in Rural Restructuring. Sage, M. London, pp. 3-26.

Woods, M., 2007. Engaging the global countryside: globalization, hybridity and the reconstitution of rural place. Prog. Hum. Geogr. 31 (4), 485-507.

Xi, J., Wang, X., Kong, Q., et al., 2015. Spatial morphology evolution of rural settlements induced by tourism. J. Geogr. Sci. 25 (4), 497-511.

Yang, R., Liu, Y.S., Chen, Y.F., 2012. Comprehensive measure and partition of rural hollowing in China. Geogr. Res. 31 (9), 1697-1706 (in Chinese).

Yang, R., Liu, Y.S., Chen, Y.F., et al., 2013a. The remote sensing inversion for spatial and temporal changes of multiple cropping index and detection for influencing factors around Bohai Rim in China. Sci. Geogr. Sin. 33 (5), 588-593 (in Chinese).

Yang, R., Liu, Y.S., Guo, L.Y., et al., 2013b. Spatial-temporal characteristics for rural hollowing and cultivated land use intensive degree: taking the Circum-Bohai Sea region in China as an example. Prog. Geogr. 32 (2), 181-190 (in Chinese).

Yang, R., Liu, Y.S., Long, H.L., et al., 2015a. Spatio-temporal characteristics of rura settlements and land use in the Bohai Rim of China. J. Geogr. Sci. 25 (5), 559-572.
Yang, R., Liu, Y.S., Long, H.L., et al., 2015b. Spatial-temporal characteristics of rura residential land use change and spatial directivity identification based on grid in the Bohai Rim in China. Geogr. Res. 34 (6), 1077-1087 (in Chinese).

Yang, R., Liu, Y.S., Long, H.L., et al., 2015c. Research progress and prospect of rura transformation and reconstruction in China: paradigms and main content. Prog. Geogr. 34 (8), 1019-1030 (in Chinese).

Yin, H., Chen, Z., 1995. Spatial distribution and evolution of the rural settlements in Shaanxi. Hum. Geogr. 10 (4), 17-24 (in Chinese).

Zhe, X.Y., 1997. Village Reconstruction: Social Changes of a Super Village. China Social Science Press, Beijing.

Zhang, D.W., 1989. Christaller and central place theory. Hum. Geogr. 4 (4), 68-72 (in Chinese).

Zhou, G.H., He, Y.H., Tang C.L., et al., 2013. Dynamic mechanism and present situation of rural settlement evolution in China. J. Geogr. Sci. 23 (3), 513-524.

Zhang, Q.F., Wu, J., 2015. Political dynamics in land commodification: commodifying rural land development rights in Chengdu, China. Geoforum. http://dx.doi.org 10.1016/j.geoforum.2015.10.001. 